\title{
O DSM-V como dispositivo de segurança
}

| ${ }^{1}$ Sandra Caponi I

Resumo: Este artigo se propõe a analisar duas críticas referidas à publicação do DSM-V, que concentraram a atenção da comunidade internacional: a crítica realizada por Thomas Insel, diretor do National Institute of Mental Health (NIMH), e a realizada por Allen Frances, que fora o chefe do grupo de tarefas da equipe que elaborou o DSM-IV. As duas críticas serão analisadas - a partir da leitura dos cursos ministrados por Michel Foucault no Collège de France, particularmente - Os Anormais, O poder psiquiátrico e Segurança, território e população. Além destas duas críticas, será analisado também o texto de Ian Hacking, Lost in the Forest, publicado após a edição do DSM-V. Hacking propõe nesse texto não nos determos numa ou outra nova categoria diagnóstica (as árvores), mas na própria estratégia de diagnóstico apresentada no Manual como um todo (a floresta).

> Palavras-chave: DSM-5; Foucault; biopolítica; risco; psiquiatria.

\footnotetext{
1 Departamento de Sociologia Universidade Federal de Santa Catarina. Florianópolis-SC, Brasil. Endereço eletrônico: sandracaponi@gmail.com
}

Recebido em: 27/12/2013 Aprovado em: 15/07/2014 
No dia 18 de maio de 2013, foi editada a última versão revisada do Manual de Diagnóstico e Estatística de Transtornos Mentais (Diagnostic and Statistical Manual of Mental Disorders), conhecida como DSM-V (APA,2013). Diversas vozes mostraram sua oposição a esta nova edição de um manual que, repetindo o modelo das versões anteriores, apresenta grandes fragilidades epistemológicas, limitando-se a elencar uma lista de sintomas pouco claros para um conjunto cada vez maior de patologias mentais.

Pesquisadores de diferentes países do mundo, como Pignarre (2006), Elisabeth Roudinesco (2013), Phillips (2010), Paris e Phillips (2013), Sadler (2010, 2013), Hacking (2013), Horwitz (2007, 2002, 2013), Conrad (2007), Braunstein (2013), junto a grupos internacionais como Stop DSM (2013), ou o coletivo francês denominado Pas zero de conduit (2013), apresentaram sólidas objeçôes a esse modelo de identificação de diagnósticos, antes e depois da publicação do DSM-V. No Brasil, se somaram críticas à estratégia reducionista do DSM por pesquisadores provenientes de campos diversos como Camargo et al. (2006), Caliman (2009), Ortega (2004, 2008), Garcia Maldonado (2012) e Dunker e Neto (2011), dentre outros.

No entanto, duas críticas publicadas imediatamente depois da divulgação do DSM-V concentraram a atenção da comunidade internacional. Ambas foram realizadas por pesquisadores americanos e se situam no interior do campo da psiquiatria. Uma delas é a crítica realizada por Thomas Insel (2013), diretor do National Institute of Mental Health (NIMH). A outra é a crítica realizada por Allen Frances (2013), chefe da equipe que elaborou o DSM-IV.

Essas duas críticas têm a peculiaridade de não terem sido publicadas em periódicos acadêmicos de alto impacto da área de psiquiatria, mas sim em veículos não tradicionais. O texto de Insel (2013) foi publicado em seu blog e os textos de Frances fazem parte de uma série de trabalhos publicados ao longo dos últimos cinco anos na revista Psiquiatric Times, que logo foram compiladas em seu livro Saving Normal (2013a) e retomadas posteriormente no capítulo de livro "DSM in Philosophyland: Curiouser and Curiouser" (2013d).

$\mathrm{O}$ fato de que essas críticas tenham aparecido em veículos academicamente não tradicionais não diminuiu o impacto das mesmas. No caso das críticas de Frances, já no ano 2010, a Association for the Advancement of Philosophy and Psychiatry 
dedicou um volume completo de seu Boletim (2010) para analisar e debater os textos publicados em Psiquiatric Times, onde Frances questionava o modo como estava sendo organizado o DSM-V. No caso de Thomas Insel, as críticas postadas em seu blog potencializaram-se pela posição institucional que ocupa. Como informado anteriormente, ele é o diretor da maior organização científica dedicada à pesquisa, compreensão, tratamento, prevenção e promoção da saúde mental, o National Institute of Mental Health (NIMH). Inclusive, o blog de Insel, onde foi postada sua crítica ao DSM-V, encontra-se na página principal do NIMH.

Considerando o impacto dessas críticas, pretendo analisar aqui os limites e dificuldades que cada uma delas apresenta, tomando como ponto de partida para esta análise a leitura dos cursos ministrados por Michel Foucault no Collège de France, particularmente, Os Anormais (1999), O poder psiquiátrico (2003) e Segurança, território e população (2004).

Além das duas críticas mencionadas, será analisado também o texto Lost in the Forest (2013), publicado por Ian Hacking imediatamente após a divulgação do DSM-V. Hacking retoma as críticas de Insel e Frances que aqui serão abordadas, insistindo na necessidade de inserir a discussão do DSM-V num processo mais amplo que tem seu início com a publicação do DSM-III (1980). Isto é, trata-se de uma abordagem que não se propõe a analisar a novidade ou a dificuldade apresentada por uma ou outra nova categoria de diagnóstico (as árvores), mas deter-se na análise das condiçóes de possibilidade e limites da estratégia de diagnóstico apresentada no manual como um todo (a floresta).

Inicialmente, será preciso lembrar que Foucault analisa em Os Anormais (1999) as condições de possibilidade discursivas e institucionais desse discurso que integrou um conjunto de fatos simples, tais como a tristeza profunda, a desatenção na infância, a excessiva preocupação com o trabalho, as alterações em nossos padrões de sono ou apetite - isto é, fatos que fazem parte da condição humana, ao campo da psiquiatria.

Sabemos que o DSM-IV, editado no ano 1994, multiplicou o número de diagnósticos psiquiátricos de acordo com sintomas clínicos bastante ambíguos, possibilitando o surgimento de novas terapêuticas, que podem ser ou não farmacológicas. Uma imensa literatura hoje está dedicada a estudar os limites e as dificuldades dessa proliferação de diagnósticos que redefinem quase 
todos nossos sofrimentos e condutas em termos médicos (HORWITZ, 2007; CAPONI, 2012; MOYNIHAN, 2006; CONRAD, 2007). O certo é que a existência inevitável de fronteiras instáveis, difusas e ambíguas entre o normal e o patológico no campo da saúde mental parece ter possibilitado o crescente processo de medicalização de condutas consideradas socialmente indesejáveis, que passaram a ser classificadas como anormais. Assistimos, assim, à crescente consolidação desse espaço de saber e de intervenção que Michel Foucault (1999) denominou medicina do não patológico.

O DSM-V se inscreve na mesma estratégia que caracteriza os Manuais ee Estatística e Diagnóstico de Transtornos Mentais desde a ruptura operada no campo da psiquiatria, no ano 1980, pelo DSM-III. A partir desse momento, começou-se a definir as patologias psiquiátricas por referência a agrupamentos de sintomas, o que acarretou a desconsideração das narrativas dos pacientes, das histórias de vida, das causas sociais e psicológicas específicas que podem ter provocado determinado sofrimento psíquico ou determinado comportamento.

\section{O poder psiquiátrico e a esperança neurológica}

Sob o título de Le pouvoir psyquiatrique (2003), Gallimard publicou a transcrição do curso ditado por Foucault no Collège do France entre os dias 7 de novembro de 1973 e 6 de fevereiro de 1974. Nesse curso, Foucault retoma a problemática da loucura de uma perspectiva completamente diferente daquela que, dez anos antes, articulara a História da loucura na época clássica (1961). Já não falará exclusivamente das representações sobre a loucura, mas dos discursos e estratégias de poder sobre as quais se edifica a psiquiatria. É esta nova preocupação própria dos estudos genealógicos, a articulação entre saber, verdade e poder, que marcará a distância entre esse texto e os estudos anteriormente dedicados à loucura e ao saber médico.

Assim, O poder psiquiátrico permite dar continuidade à História da loucura na época clássica (1961) e ao Nascimento da Clínica (1987) e, ao mesmo tempo, possibilita uma aproximação e uma articulação entre esses dois textos. $O$ poder psiquiátrico mostra ainda a dificuldade em se separar a história da psiquiatria e da história da medicina. Mesmo quando existem práticas, modos de observar e de diagnosticar absolutamente diferentes, é em relação à medicina que a psiquiatria encontra sua legitimidade e seu prestígio: 
Tendemos a pensar que a psiquiatria aparece pela primeira vez como uma especiali-

dade no interior do domínio médico [...]. Entretanto, entre os fundadores da psiquiatria, a operação médica que estes realizam quando tratam de um paciente não tem, em sua morfologia nem em sua disposição geral, virtualmente, nada a ver com aquilo que se está transformando na experiência, a atividade diagnóstica, e no processo terapêutico da medicina. Seus procedimentos são absolutamente irredutíveis aos da medicina (FOUCAULT, 2003, p. 14).

No entanto, é com relação ao hospital, à anatomopatologia e ao nascimento da clínica que deve ser compreendido o discurso psiquiátrico: "É essa heterogeneidade que vai marcar a história da psiquiatria” (FOUCAULT, 2003, p. 15).

Foucault analisa ambas as disciplinas (psiquiatria e medicina) observando aquilo que as aproxima e aquilo que as separa. Mostra que é necessário se deter nas diferenças, entre a figura do médico e a figura do psiquiatra, entre a instituição hospitalar e o asilo, entre as práticas próprias da psiquiatria e aquelas realizadas por um anatomopatologista ou um clínico, no mesmo momento histórico. Detém-se nas diferentes estratégias terapêuticas e nos diferentes modos de estabelecer um diagnóstico. E é nesse contexto que se deve situar a crítica realizada por Thomas Insel ao DSM-V.

Certamente, dentre os debates internacionais suscitados a propósito do DSM-V, a crítica que teve maior impacto foi a realizada pelo diretor do National Institute of Mental Health (NIMH) quando, pouco antes da publicação da quinta versão do manual, Thomas Insel (2013) anunciava que este instituto abandonaria a utilização da classificação proposta pela APA (American Psychiatric Association). Argumentava que, por se tratar de uma lista de sintomas sem sustento científico sólido, o DSM não seria mais utilizado como marco de referência para as pesquisas científicas financiadas por esse instituto. Muitos receberam com esperança essa declaração que parecia indicar o fim da hegemonia classificatória do DSM. Porém, uma leitura atenta da posição defendida por Insel é ainda mais perturbadora do que poderia ser a própria reedição do DSM.

Essa crítica, na verdade, nada agrega a um debate que a cada dia parece ser mais necessário. Muito pelo contrário, essa crítica retoma os postulados localizacionistas e deterministas que caracterizaram a psiquiatria biológica, iniciada em 1830 com a Frenologia de Gall, tendo sua continuidade com os estudos de Charcot e consolidando-se, no início do século XX, com Kraepelin, considerado até hoje como o pai da psiquiatria moderna. Em todos e em cada um 
destes esforços, por achar a localização cerebral, ou a explicação neuroquímica para transtornos mentais, a resposta parecia ser a mesma: "ainda não foi possível atingir os resultados esperados, mas um futuro promissor se anuncia para a explicação biológica de patologias mentais". Este futuro promissor que a psiquiatria ainda continua aguardando, a esperança ingênua na possibilidade de identificar nossos processos de subjetivação e nossos sofrimentos em alteraçôes cerebrais específicas, detectáveis pela mediação de marcadores genéticos ou diagnósticos por imagem, é o argumento que se repete, mais uma vez, na crítica do diretor do National Institute of Mental Health (NIMH).

Insel dirá que as diferentes versões do DSM, longe de serem consideradas como "a Bíblia da psiquiatria", como muitos qualificaram o manual, deveriam ser consideradas um simples dicionário que pode ser alterado a partir de acordos estabelecidos, neste caso, pela comunidade de psiquiatras. Diferente de patologias como Aids, câncer de pulmão ou doença de Chagas, não temos aqui marcadores biológicos definidos, mas suposições e convenções. Por essa razão, Insel pôde afirmar que "A debilidade do DSM está dada por sua falta de validade" (INSEL, 2013, p. 2), isto é, por sua falta de referência a estudos de laboratório capazes de validar os diagnósticos. Nada impede, nenhum marcador biológico, que essas classificações sejam alteradas e modificadas por consenso, pois elas são, como afirmaria Desrosières (2010), "convenções coletivas de equivalência”, realizadas com o objetivo de criar uma linguagem comum, universal, sobre a qual se poderão estabelecer processos de medição e comparação.

Insel sustenta que o National Institute of Mental Health (NIMH) deve abandonar o DSM como referência para as pesquisas, pois "os pacientes com transtornos mentais merecem algo melhor”. A questão está em saber o que se entende por "algo melhor". Será que finalmente se pedirá à psiquiatria que reconheça a urgente necessidade de substituir as fichas de diagnóstico e a contagem de sintomas pela história de vida dos sujeitos que padecem de sofrimentos psíquicos? Será que se trata de substituir uma arbitrária e convencional estratégia de agrupamentos de comportamentos (considerados como sintomas) pela escuta atenta à narrativa dos pacientes, a fim de auxiliar no complexo processo de construção de sua subjetividade? Certamente que não. O que para Insel significa "algo melhor" não é mais do que um retorno aos sonhos frustrados do século XIX, quando a psiquiatria surgiu como um espaço de saber que toma emprestado 
do saber médico sua dignidade e prestígio. Inicia-se então o processo, sempre inacabado e frustrado, de aproximar-se e identificar-se com os procedimentos e modelos utilizados pela medicina clínica geral.

A ideia de um conhecimento diferencial da loucura, fundada sobre a anatomopatologia, a fisiopatologia ou a neurologia, esta tentativa de inscrição da loucura no interior de uma sintomatologia médica geral terminará por fracassar no século XIX. "O fracasso desta tentativa de Charcot, o fato do corpo neurológico fugir da psiquiatra, como também foge o corpo anatomopatológico, limitará o saber psiquiátrico a três instrumentos de poder: a hipnose, os interrogatórios e as drogas" (FOUCAULT,2003, p. 303).

É esse fracasso o que Thomas Insel não está disposto a admitir. Para ele, de acordo com as bases que sustentam a proposta do Research Domain Criteria (RDoC), a psiquiatria deve concentrar seus esforços na criação de uma nova nosologia, que deverá transformar os diagnósticos pela incorporação de estudos genéticos, de imagens cerebrais e de referências às ciências cognitivas. Lembremos que o Research Domain Criteria (RDoC) é um projeto de pesquisa de longa escala, organizado pelo National Institute of Mental Health (NIMH), cujo diretor é Thomas Insel, que tem como objetivo estabelecer bases neurológicas para as classificações psiquiátricas. Esse projeto parte das seguintes premissas, que, como veremos, são as mesmas que, de acordo com Foucault, deram nascimento à psiquiatria moderna: 1) construção de diagnósticos baseados na biologia e não na sintomatologia (como o DSM); (2) a suposição de que os transtornos mentais são transtornos biológicos que envolvem circuitos cerebrais (ao que poderíamos responder que todos nossos atos, pensamentos, movimentos, sonhos etc. também envolvem circuitos cerebrais); e (3) a expectativa de que o mapeamento dos aspectos cognitivos, dos circuitos cerebrais, e dos aspectos genéticos das desordens mentais pode vir a produzir novos e melhores alvos para os tratamentos (INSEL, 2013).

Insel dirá que o DSM-V não poderá ser utilizado como "padrão ouro", pois corre-se o risco de limitar e fechar as portas para um sistema que pretende ser biologicamente fundado, ainda que até hoje não exista nenhuma resposta conclusiva dos estudos biológicos para as patologias mentais. Não se trata então de deixar maior espaço para o entendimento dos sofrimentos individuais do que era permitido nos DSM-III ou IV; o que o Instituto Americano de Saúde Mental 
demanda é uma flexibilidade maior, para poder criar novos agrupamentos classificatórios que servirão de alvo para a criação de novos fármacos capazes de agir sobre esses transtornos que sempre e necessariamente estarão referidos a déficits neuroquímicos ou genéticos. Assim, quando Insel afirma que "o paciente merece alguma coisa melhor", ele quer dizer que o paciente merece que algum dia se cumpra o sonho sempre postergado de identificar os procedimentos da psiquiatria com os da medicina.

Imaginar que nossos sofrimentos psíquicos podem ser tratados como uma úlcera ou uma infecção significa simplesmente negar que os sofrimentos devam inscrever-se numa história de vida, que esses sofrimentos se transformarão ao longo de nossas vida e que nesta transformação tem papel fundamental o modo como somos ouvidos e as intervençôes e terapêuticas que nós são propostas.

Se o curso de Michel Foucault, $O$ poder psiquiátrico (2003), nos permite entender os limites e as fragilidades da crítica que o National Institute of Mental Health (NIMH) realiza ao DSM, é o curso Segurança, território e população (2004), e mais especificamente o conceito de biopolítica tal e como foi analisado nesse curso, que servirá de auxílio para analisar a segunda crítica que, desde o próprio campo da psiquiatria, foi realizada ao DSM-V. Uma critica que, de fato, bem poderia estar dirigida a qualquer uma das anteriores edições do DSM, pelo menos aquelas que se sucederam a partir do DSM-III.

\section{Biopolítica, risco e segurança}

Foucault, em sua obra $A$ vontade de saber (1978), aborda o tema da biopolítica em relação à sexualidade e às políticas higiênicas e eugênicas próprias dos estados modernos. Paralelamente, o autor dedicará os cursos do Collège do France Em defesa da sociedade (1997) e Segurança, território e população (2004) a tematizar outros dois eixos articuladores da biopolítica. No primeiro caso, relacionará a biopolítica com a problemática das raças e com as estratégias racistas que marcaram os processos de expansão colonial próprios do século XIX. No segundo caso, tematizará o lugar em que a estrutura segurança-prevenção-risco, que caracteriza as sociedades modernas e contemporâneas, ocupa como eixo articulador da biopolítica das populaçôes nos estados liberais e neoliberais.

Os eixos raça, sexo, segurança e risco aparecem nesses textos como espaços privilegiados a partir dos quais se constrói a distinção entre as populações que 
devem ser maximizadas e aquelas que parecem estar condenadas ao esquecimento e ao silêncio. A expressão que Foucault utilizará para ilustrar o diagrama de poder que caracteriza a biopolítica será, como já é sabido, "fazer viver e deixar morrer", por oposição ao poder soberano, próprio das monarquias absolutas, edificado em torno da poder real de "fazer morrer e deixar viver" (FOUCAULT, 1978).

Fazer viver e deixar morrer será o princípio que definirá o exercício de poder nos Estados liberais e neoliberais. Um princípio que supõe a oposição entre populaçôes que se destinam a esquemas de higiene, segurança e proteção, e outras que simplesmente são ignoradas, ou que são alvo de estratégias de silenciamento, exclusão e controle. Estas últimas serão estatisticamente definidas como anormais ou desviantes. Desse modo, inaugura-se um olhar médico sobre os fatos sociais, isto é: "uma maneira de perceber as coisas que se organizam ao redor da norma, que procuram marcar o que é normal e o que é anormal. Pois, enquanto o pensamento jurídico distingue o lícito do ilícito, o pensamento médico distingue o normal do anormal" (FOUCAULT, 1997, p. 34).

Em O nascimento da biopolítica (2005), Foucault interroga:

Como é possível garantir o exercício do governo nas sociedades liberais e neoliberais? Como governar uma população composta por sujeitos que se definem como Homo economicus, isto é, como sujeitos capazes de tomar decisões racionais para atingir as metas desejadas? Claro que não será por uma vigilância externa e contínua como era exigido no poder disciplinar (FOUCAULT, 2005, p. 325).

A resposta de Foucault será dada "pela lógica do risco e da segurança”. Ele analisa esse novo modo de organizar o sistema de gestão e de administração das populações interessado em antecipar os riscos e temores suscitados pela circulação de homens e de mercadorias como sendo o eixo central em torno do qual se articula o modo com os Estados liberais governam.

É nesse espaço de análise que pretendo situar a crítica realizada por Allen Frances ao DSM-V. O autor aponta as dificuldades implícitas no DSM-V, considera que esse manual se caracteriza por apresentar uma lista de patologias mal formuladas, de modo pouco claro e inconsistente. E ainda, por acrescentar à lista já excessiva de diagnósticos presentes nas anteriores edições, novas patologias associadas à prevenção e antecipação de riscos, tal e como seria o caso de "risco de psicose", ou a detecção precoce de doenças mentais em crianças.

Será justamente em torno da problemática do risco e do "dispositivo de segurança” que Foucault pensará o exercício da biopolítica nas sociedades liberais 
e neoliberais. A biopolítica é situada neste espaço de diálogo onde podemos identificar alguns dos mecanismos que permitem observar como opera o modo de exercício do poder no campo da psiquiatria atual. Estes mecanismos são: (1) a centralidade da norma e a oposição normalidade-patologia; (2) os estudos estatísticos referidos aos fenômenos vitais que caracterizam as populações; (3) a problemática do risco-segurança, isto é, a ideia de que é possível antecipar os riscos para evitar a emergência de futuros danos. Estes mecanismos configuram um peculiar modo de exercer o governo sobre as populações que exclui as narrativas dos sujeitos e suas histórias de vida. A gestão das populações enquanto multiplicidade biológica deve deixar nas sombras, como antecipara Aristóteles, nossa capacidade de existência pública e política, os diálogos argumentativos, as narrativas individuais, os vínculos sociais.

Reaparecem então, um a um, os mecanismos aos quais Allen Frances dirige sua crítica quando analisa o DSM-5. Porém, e como tentaremos mostrar, esses mecanismos são centrais e articuladores também de todos os manuais anteriores, incluindo o DSM-IV, de cuja elaboração Frances participou de modo direto. As críticas de Allen Frances ao DSM-V começaram a ganhar difusão e impacto no ano de 2010 com a publicação de seu artigo "Abrindo a caixa de Pandora: as 19 piores sugestôes do DSM-V", quando ainda o manual se encontrava em processo de discussão e elaboração. Essas críticas deram lugar a um livro de Allen Frances (2013a), denominado Saving Normal: an insider's revolt against out-of-control psychiatric diagnosis, DSM-V, bg pharma, and the medicalization of ordinary life. Após a edição do manual, Frances publicou diversos artigos críticos destinados a apontar sérias fragilidades encontradas no DSM-V. Estas fragilidades são divididas em dois grupos: um que se refere a escolhas conceituais erradas como, por exemplo, behavioral addictions (comportamentos aditivos) ou binge eating (traduzido como transtorno de compulsão alimentar periódica); o outro grupo se refere aos erros no processo de elaboração e redação do manual, indefinições ou periodizaçôes inconsistentes e superpostas para algumas patologias. Este é o caso, por exemplo, do Disruptive Mood Sysregulation, cuja definição apresenta quatro grupos etários confusos e superpostos. São eles: mais de 12 anos; entre 6 e 18 anos; antes dos 10 anos; e entre 7 e 18 anos (FRANCES, 2013c, p. 1).

Antes da publicação do DSM-V, Frances dirigiu sua crítica, fundamentalmente, a uma categoria que considerava particularmente frágil e problemática: Psychosis 
Risk Syndrome (síndrome de risco de psicose). Esta categoria será de fato excluída

do DSM-V, porém, como afirma o próprio Frances, retornará com as mesmas fragilidades e os mesmos problemas, como uma categoria que se inscreve no grupo abrangente do Schizoprenia Spectrum, com uma nova denominação, Attenuated Psychosis Syndrome, uma nova sigla (APS). Assim, no texto recentemente publicado, "Psychosis risk syndrome is back to haunt us", lemos que:

A única maneira de evitar os perigos do DSM-V é estar plenamente conscientes deles. Não faz absolutamente nenhum sentido fixar o rótulo enganoso e estigmatizante "Other Specified Schizophrenia Spectrum Disorder"'em alguém que, em configuraçôes típicas, terá apenas cerca de $10 \%$ de chance de se tornar psicótico. E, certamente, não faz sentido seguir esse diagnóstico errado com tratamentos antipsicóticos sem comprovação e potencialmente muito prejudiciais (FRANCES, 2013b, p. 1).

Defato, esse texto de Frances pode ser entendido como uma crítica às dificuldades implícitas aquilo que Foucault denominou "dispositivo de segurança”. A crítica de Frances permite pensar o DSM-V como uma estratégia biopolítica, isto é, como uma estratégia de gestão e governo das populações própria das sociedades liberais e neoliberais que se articula em torno à obsessão por antecipar e prevenir todos os riscos possíveis. É preciso reconhecer que essa característica não é exclusiva do DSM-V, como desejaria Frances, mas que pode ser extensiva às anteriores edições do DSM, por exemplo, quando se afirma que a existência de um ou mais sintomas (dos nove elencados no DSM-IV) para depressão indica já a existência de risco de vir a sofrer um episódio depressivo no futuro.

Os mecanismos que permitem pensar o DSM como estratégia biopolítica são de três tipos. O primeiro é a existência inevitável de fronteiras difusas e pouco claras entre normalidade e patologia psiquiátrica. O que cria um território sem limites epistemológicos definidos, sem marcadores, nem testemunhas confiáveis. É justamente essa ambiguidade que permite a crescente multiplicação de diagnósticos psiquiátricos. Em diversos textos e dando continuidade ao que afirmara em "Abrindo a caixa de Pandora, as 19 piores sugestôes do DSM-V", Frances afirma que o do DSM-V anuncia a aparição de uma verdadeira pandemia de transtornos mentais (FRANCES, 2010,2012, 2013):

O DSM5 poderia criar dezenas de milhōes de novos mal identificados pacientes "falso positivos" exacerbando assim, em alto grau, os problemas causados por um já demasiado inclusivo DSM-IV. Haveria excessivos tratamentos massivos com medicações desnecessárias, de alto custo e frequentemente bastante prejudiciais (FRANCES, 2010, p. 2). 
$\mathrm{O}$ fato de que essas propostas levaram a classificar inadequadamente com o rótulo de "transtorno mental" milhões de pessoas que antes eram consideradas "normais" não é novo, não é acidental, nem resultado de uma escolha metodológica equivocada, realizada pelo Grupo de Tarefas do DSM-V. Pelo contrário, tratase de uma questão teórica e política que é contemporânea à própria ambição classificatória da psiquiatria.

O incremento das taxas de transtornos mentais na população ocorre, sustenta Frances, de dois modos: (1) pela criação de novos diagnósticos que transformam em patológicos comportamentos comuns na sociedade, que a indústria farmacêutica se encarregará de popularizar (como a tristeza, os pequenos déficit de cognição, as explosões de raiva, os comportamentos sexuais, as adições a certas condutas cotidianas como comprar, o uso de sustâncias tóxicas, etc.); (2) estabelecendo um limiar de diagnóstico mais baixo para muitas patologias já existentes, como de fato ocorreu ao retirar a excepcionalidade concedida aos casos de luto para o diagnóstico de depressão (FRANCES, 2010; 2013). Neste caso, ocorreu uma alteração significativa no manual anterior, enquanto no DSM-IV o luto era considerado uma situação excepcional na qual a aparição dos sintomas podia estender-se por dois meses, no caso DSM-V esta excepcionalidade desaparece, ficando por conta do clínico a avaliação de cada situação concreta (APA, 2013, p. 162). Não é difícil descobrir que essas estratégias já estavam presentes nas anteriores edições do manual. De acordo com Frances:

O maior impacto do DSM-V partiria da sugestão de eliminar o critério de "significação clinica" que era requerido no DSM-IV para os transtornos onde existem limites difusos com a normalidade (aproximadamente dois terços dos diagnósticos). Eliminando esse requerimento, se reduziria o papel do julgamento clínico [...], incrementando as já inflacionadas taxas de diagnósticos psiquiátricos (FRANCES, 2012, p. 3).

Uma pergunta surge de modo inevitável: quem substitui o julgamento clínico do especialista? Quem determina se certa situação de angústia ou impedimento indicam ou não a existência de uma patologia psiquiátrica uma vez eliminado o critério de "significação clinica"? Encontramos aqui o segundo mecanismo articulador da biopolítica, o uso das estatísticas, das médias e desvios populacionais. $\mathrm{O}$ que substitui a avaliação da significação clinica são as novas estratégias diagnósticas, com maior pretensão de objetividade, que incluem a aplicação de testes e de checklist, as valoraçôes dimensionais para rasgos de personalidade, as 
pontuações de severidade - enfim, todo um arsenal quantitativo que já estava presente nas anteriores edições do DSM e que no DSM-V se intensifica.

De acordo com Dunker e Neto, a "perspectiva de basear a prática clínica pela eficácia leva à hipervalorização da chamada "Medicina Baseada em Evidências" (MBE). A noção de eficácia na MBE está associada ao tratamento em condições de mundo ideal, ou seja, a supressão dos sintomas" (DUNKER; NETO, 2011, p. 622).

Tomando como ponto de partida esse conjunto de estatísticas e as taxas de prevalência que cada transtorno apresenta, será construído o que pode ser identificado como sendo o terceiro mecanismo que caracteriza a biopolítica. É possível afirmar que uma das estratégias indispensáveis para garantir a indefinida ampliação de diagnósticos e categorias psiquiátricas é a obsessão por identificar pequenas anomalias, angústias cotidianas, pequenos desvios de conduta como indicadores de uma patologia psiquiátrica grave por vir. $\mathrm{O}$ risco, na medida em que aparece como um modo de antecipar um perigo possível (real ou imaginado) sobre a vida e a saúde, constitui a estratégia biopolítica por excelência que permite garantir a legitimidade e aceitabilidade desse modo de exercer o governo das populaçôes (CASTIEL, 2012).

Os psiquiatras esperam identificar pacientes mais cedo e criar tratamentos efetivos
para reduzir a cronicidade das patologias. Desafortunadamente, os membros do
Grupo de Tarefas usualmente cometem o erro de esquecer que qualquer esforço por
reduzir as taxas de falsos negativos deve elevar as taxas de falsos positivos de modo
dramático e com fatais consequências. Se alguma vez será possível chegar à esperada
vantagem da deteç̧ão precoce de casos, deveremos ter provas diagnósticas específicas
e tratamentos seguros. Em contraste, as propostas do DSM-V, levam à uma perigosa
combinação de diagnósticos não específicos, inadequados, e a tratamentos não apro-
vados e danosos (FRANCES, 2010, p. 6).

Assim, ainda que Frances admite que a tarefa de ler o manual completo é uma empresa quase impossível, dirá que é muito simples identificar seus erros, pelo menos um a cada página, criando grande confusão e permitindo a ampliação desnecessária de diagnósticos (FRANCES, 2013b, p. 2).

Em 2010 Frances afirmava, por referência à síndrome de risco de psicose, que a existência desse diagnóstico provocaria uma alarmante taxa de falsos positivos de 70 a 75\%, levando milhares de adolescentes e jovens a receber, sem necessidade, a prescrição de antipsicóticos atípicos que causam efeitos colaterais sérios como 
aumento de peso, impotência sexual e redução da expectativa de vida. Após a edição do manual, esses mesmos problemas permanecem. Entende-se que o diagnóstico de Attenuated Psychosis Syndrome (APA, 2013, p. 785) não é mais que outro nome para o risco de psicoses. Poderíamos acrescentar também que o código (298.8) referido a Other Psychotic Disorders (APA, 2013, p. 87) poderia vir a substituir também a categoria Sindrome de risco de psicose. Frances afirma:

A prevenção da psicose seria uma ótima ideia se realmente fosse possível fazê-la, mas não há nenhuma razão para se pensar nisso. Ir além de nossa compreensão provavelmente afetará aqueles que esperávamos ajudar. O Risco de Psicose não deve ser usado como um diagnóstico clínico, pois estará quase sempre errado. A estrada para o inferno está pavimentada de boas intenções e de más consequências não intencionais. Primeiro, não causar dano. (FRANCES, 2013c, p. 1).

Foucault nos auxilia a compreender de que modo, e respondendo a que lógica foi construída a estratégia analítica que Frances apresenta de modo crítico, ainda que ela também tenha sido utilizada exatamente do mesmo modo pelo grupo de tarefas que ele coordenava. Foucault aponta uma série de elementos presentes na construção dos dispositivos de segurança, dentre eles: realizar, pela mediação das estatísticas, cálculos diferenciais de risco por idade, sexo, profissão, etc.; estabelecer diferentes curvas de normalidade; calcular os desvios e criar estratégias de normalização; definir populações de risco e comparar padrões de morbidade e mortalidade; criar intervenções preventivas, capazes de reduzir os indicadores de morbidade, de reduzir os desvios e de antecipar os riscos. Muitos desses elementos parecem ser constitutivos do DSM quando observamos o papel central que ocupa a prevenção e antecipação de riscos, isto é, a ideia de interferir antes que a patologia mental se cronifique e se torne irreversível. $\mathrm{O}$ subitem denominado Risk and Prognostic Factors que aparece na descrição de cada patologia ou de cada grupo de patologias evidencia o papel central que os dispositivos de segurança ocupam no manual.

Saber antecipar os riscos, estar devidamente informado e agir de acordo às exigências impostas pelos últimos estudos epidemiológicos, psiquiátricos e médicos, se impõe como um dever moral a todos nós e de maneira idêntica. Se o dispositivo de segurança pode articular-se com o modo liberal de governar, é porque este tipo de gestão biopolítica das populações se baseia na confiança absoluta, na difusão de informações que se apresentam como neutrais e objetivas, e que sutilmente somos levados a aceitar e a integrar a nossas vidas. A múltiplas 
categorias diagnósticas que aparecem nos sucessivos DSM a partir do ano 1980

fazem parte desta lógica securitária que promete antecipar o risco de sofrer uma patologia mental grave no futuro.

$\mathrm{O}$ que Frances parece esquecer é que a mesma estratégia de antecipação de riscos que se aplica no caso do Attenuated Psychosis Syndrome possibilitou que o DSM-IV participasse ativamente do crescente processo de multiplicação de patologias mentais na infância (TDAH, dislexia, ansiedade, dentre outras). Em ambos os casos, opera-se uma mesma lógica securitária de identificação precoce de riscos que, supostamente, permitiria antecipar a emergência de patologias mentais irreversíveis, assim como permitiria prevenir atos de violência dirigidos aos outros ou a si mesmo, podendo chegar a limites como o homicídio ou o suicídio. Mas o fato incontestável de que a problemática do risco e o dispositivo de segurança faz parte da própria lógica de construção do DSM fica evidente quando lemos o reconhecimento que, não sem certo cinismo, Frances faz de um erro cometido na elaboração do DSM-IV:

Exemplo - o meu maior arrependimento sobre DSM-IV foi a nossa substituição inadvertida do que era um 'e' para um 'ou' nos critérios estabelecidos para parafilia. Este deslizamento estúpido contribuiu para a prisão preventiva inconstitucional de milhares de criminosos sexuais. Eu não tenho pena de criminosos, mas tenho grande preocupação quando os direitos constitucionais são violados só porque eu cometi um estúpido erro de redação. (FRANCES, 2013b, p. 1).

Em outro contexto, a problemática do risco e a ambição pela detecção precoce de indivíduos em risco de padecer uma patologia psiquiátrica que poderia ser prevenida antes que se cronifique têm levado a um processo maciço de medicalização da infância que se amplia a cada nova edição do DSM.

Quando interrogado sobre a relação dos membros da APA com a indústria farmacêutica, Frances nega qualquer interferência e formula a sugestiva pergunta: "Como podem pessoas tão inteligentes e escrupulosas (referindo-se a seus amigos e colegas do Grupo de Tarefas) fazer tantas sugestões ruins?” (FRANCES, 2012, p. 5). Ele responde:

Tem sido minha experiência consistente (obtida trabalhando nos três prévios DSMs) que cada grupo de Trabalho tem sempre uma forte (frequentemente irresistível) ânsia de expandir os limites das desordens de sua seção. Esse previsível imperialismo de diagnóstico dos Grupos de Tarefa deve ser sempre reconhecido e resistido. Os especialistas tem muita expectativa em reduzir os falsos negativos para seus transtornos favoritos e em anular a necessidade de recorrer à etiqueta "não especificado de outro modo". 
Dificilmente poderemos chegar a ter um exemplo mais claro do modo como opera a biopolítica dos comportamentos cotidianos e dos sofrimentos psíquicos leves. Enuncia-se ali uma aliança indissociável entre um discurso de verdade (uma classificação diagnóstica cujos limites se expandem cada vez mais), e uma estratégias de poder (centrado no "dispositivo de segurança").

\section{Perdidos na burocracia}

Para concluir, gostaria de fazer uma brevíssima referência, que será aprofundada em outros estudos, ao texto Lost in the Forest, publicado por Ian Hacking (2013) no dia 8 de agosto de 2013 na London Review of Books. O texto permite retomar as críticas dirigidas ao DSM-V que foram aqui analisadas a partir de outra perspectiva. Hacking refere-se rapidamente em seu texto às críticas realizadas por Allen Frances e Thomas Insel.

Hacking dirá que a crítica de Insel, ainda que tenha sido recebida com grandes expectativas, não apresenta significativa oposição ao modelo apresentado pelo DSM-V. Aquilo que parecia indicar, inicialmente, o inicio do fim do manual apresenta, no entanto, uma posição perfeitamente compatível com o DSM. De fato, ainda considerando todas as observações de Insel ao manual, poder-se-ia continuar utilizando-o de modo direto no campo da clínica (na medida em que é um manual dirigido a clínicos) e indiretamente tanto nos estudos epidemiológico comparativos, quanto na própria gestão dos serviços de saúde e na organização das seguradoras médicas e sociais.

Para Hacking, a nova classificação que promete ser elaborada pelo NIMH para servir de base às pesquisas biológicas pode conviver perfeitamente com a proposta apresentada pelo DSM-V. Pode-se imaginar que as duas classificações conviverão por um tempo, até que as pesquisas biológicas demonstrem ser suficientemente robustas para que ambas as classificações procurem estratégias de unificação.

A critica de Hacking centra-se em um ponto, na afirmação de que o DSM não se refere a "tipos naturais", que não se refere a patologias com uma identificação precisa como seria uma gripe, a Aids ou uma úlcera. Essa crítica se resume ao seguinte: "O DSM não é a representação da natureza ou da realidade da variedade de doenças mentais e essa é uma critica muito mais radical que a falta de validade imputada por Insel” (HACKING, 2013). No entanto, a crítica de Hacking e a crítica de Insel se aproximam, ainda que se encaminhem para direções opostas. 
Lembremos que para Insel, e o mesmo será para Hacking: o DSM não deve ser

considerado como a "Bíblia da psiquiatria", e sim como um dicionário construído a partir de debates e consenso entre os atores que participaram de sua elaboração. De fato, essa parece ser uma crítica frágil e até impertinente, pois o DSM sempre se apresentou a si mesmo como uma lista descritiva, ateórica e sujeita a revisão, de transtornos estabelecidos por um processo de consenso entre pares. Mas as semelhanças param aí, pois enquanto Insel encontra a fragilidade epistemológica de um sistema que está disposto a substituir uma classificação que tenha por referência o que ele considera "patologias mentais com base biológica definida", Hacking, ao contrário, não compartilha desta confiança, não acredita que exista ou deva vir a existir um modelo médico para todos os sofrimentos. "Para aqueles de nós que duvidamos da aplicabilidade do modelo médico propiciado pelo NIMH para todo tipo de patologia mental, existe, de fato, um motivo de preocupação" (HACKING, 2013).

Pode-se dizer que o grande erro do DSM é, aos olhos de Hacking, sua pretensão de ser espelho da realidade tal e como seriam as classificações botânicas. Assim, referindo-se às várias evidências de comorbidade presentes no campo da psiquiatria, Hacking afirmará: "Isso nos mostra que a classificação das doenças mentais não é em absoluto igual à classificação de animais, vegetais ou minerais. Refiro-me à distinção de gêneros, espécies e subespécies" (HACKING, 2013). E este é um fato que não se resolverá, como acredita Insel, com maiores pesquisas biológicas ou genética. No entanto, de acordo com a leitura de Hacking, esse fato não invalida a operatividade do DSM-V como instância burocrática: "Mantém-se um livro muito útil para outros fins. É essencial contar com algo como isto para suprir as necessidades burocráticas de pagar por tratamentos e para as avaliaçôes de prevalência” (HACKING, 2013).

Nesse sentido, o que não deixa de causar surpresa no texto Hacking é o quão escassamente "hackingniana" é a leitura do DSM apresentada em Lost in the forest. A conclusão de Hacking parece nos conduzir à aceitação de uma função administrativa e burocrática do manual. Afirma que, para esses fins burocráticos, como pagar tratamentos e seguros médicos, não existem grandes diferenças nas diversas versóes do manual. Hacking parece falar como se a burocracia estivesse desvinculada dos estudos epidemiológicos e da medicina baseada em evidencia que pouco a pouco substitui o olhar clínico (como vimos nos parágrafos dedicados 
a Frances), ou como se, simplesmente, essas estratégias burocráticas não tivessem consequência na atribuição de diagnósticos para sofrimentos cotidianos e na prescrição de terapias farmacológicas. Como afirma Miguel Kottow:

Para Hacking, o DSM poderia cumprir importantes funçōes burocráticas, sem que deva ser utilizado na clínica psiquiátrica enquanto não haja necessidade de preencher formulários. Provavelmente Hacking seja excessivamente tolerante em desatender as consequências sociais e medicalizantes que implica atribuir etiquetas de enfermidade a condiçôes como homossexualidade, estresse agudo, menopausa, duelo prolongado. (KOTTOW, 2013, p. 309).

É verdade que o objetivo último da criação do DSM, particularmente dos DSMs que se sucederam a partir de 1980, foi construir uma "convenção coletiva de equivalência” que permitisse criar uma linguagem comum, universal, para estabelecer processos de medição, comparação e burocratização. Porém, ninguém melhor do que Hacking para explicar esse processo pelo qual as classificaçóes produzem modos de ser sujeito. Ninguém melhor do que Hacking para falar sobre o efeito de looping ou de feedback (seja negativo ou positivo) que os processos de classificação e diagnóstico produzem sobre os sujeitos diagnosticados.

É justamente Hacking quem afirma, lembrando Nietzsche, que o nome que damos às coisas importa infinitamente mais do que elas são, que basta criar nomes e classes para criar tipos de pessoas, modos de ser sujeito. Nas palavras de Hacking:

Os sistemas atuais de diagnóstico e de tratamento contribuem para produzir o tipo de comportamento anormal característico de uma determinada doença. Classificação e diagnóstico são categorias historicamente construídas e essa construção interage com as pessoas e contribui para produzir certos comportamentos que, por sua vez, podem confirmar o diagnóstico (HACKING, 2006, p. 7).

Assim, quando afirma que o DSM é necessário como estratégia burocrática, Hacking parece esquecer de Hacking. Isto é, parece esquecer que para que uma convenção coletiva de equivalência possa transformar-se numa categoria classificatória, ela deve estar situada no interior de certas instituições e de certos sistemas peritos que as legitimem. Para que essa classificação tenha os efeitos performativos que ele tão bem analisou em Making up people (2006), é necessário que ela esteja validada por instâncias científicas e burocráticas de legitimação. Uma palavra não cria sujeitos, uma classificação reconhecida pelo Estado, pelos seguros de saúde e pela mídia; terá sim efeitos performativos, poderá produzir efeitos de identificação ou rejeição. 


\section{Considerações finais}

O certo é que, para que os diagnósticos (TDAH, depressão) se diferenciem dos simples adjetivos qualificativos (criança impossível, mulher triste), eles deverão iniciar seu curso como categorias burocráticas que logo interagirão com os indivíduos que, por sua vez, se identificarão ou não com esses diagnósticos. Muitas vezes, essas categorias se impõem até com a força da lei, como ocorre quando crianças diagnosticadas como hiperativas são obrigadas pelas instituições escolares ou outras instâncias de governo a tomar uma medicação. Sempre existirá, como também afirma Hacking, a possibilidade de se negar a aceitar uma categoria diagnóstica. Porém, são justamente as estruturas burocráticas, para as quais Hacking reserva a utilidade do DSM, as que limitam e reduzem a possibilidade de pensar nossos sofrimentos como decorrentes de circunstâncias concretas de vida que seria preciso modificar ou alterar.

Como muitos profissionais de saúde relatam frequentemente, é negado a eles, pelo pouco tempo de que dispõem para realizar as consultas, a possibilidade de escutar as narrativas de vida de seus pacientes, restringindo-se ao relato dos sintomas (DUNKER; NETO, 2011). Sabemos que em muitos casos, tal como ocorre com a depressão, o conjunto de sintomas que leva ao diagnóstico é frequentemente o "denominador comum" (PIGNARRE, 2006) de situações de vida que pode ser fatal desconsiderá-las como a violência familiar, ou o assédio moral no trabalho. Porém, independentemente da pluralidade dos contextos em que emergem os sofrimentos, dado um conjunto semelhante de sintomas (alteração de sono e apetite, sentimento de infelicidade ou culpa, tristeza profunda), todos os casos (ou a grande maioria) tenderão a receber um mesmo diagnóstico de depressão, um mesmo código burocrático e uma mesma (ou semelhante) medicação, como um ISRS, independentemente das circunstâncias concretas de vida. O DSM opera, assim, como um dispositivo de segurança que reduz todos os nossos sofrimentos à lógica da intervenção biomédica, à lógica da prevenção e da detecção de riscos (que será no caso da depressão o risco de suicídio).

Acredito que, como afirmam Elisabeth Roudinesco (2013) ou Phylippe Pignarre (2006), dentre outros, é necessário abandonar o DSM como modelo hegemônico de diagnóstico no campo da psiquiatria. $\mathrm{O}$ manual necessariamente reduz os sofrimentos individuais a uma lista de sintomas ambíguos e pouco claros 
para um conjunto, cada vez maior, de patologias mentais. É preciso inventar estratégias que nos permitam compreender que os sofrimentos psíquicos só podem tornar-se inteligíveis no interior de uma história de vida. Somente a escuta atenta das narrativas de nossos ódios e amores, de nossos medos, conquistas e fracassos poderá nos auxiliar na difícil e infinita tarefa de construção e reconstrução de nossa subjetividade.

\section{Referências}

AMERICAN PSYCHIATRIC ASSOCIATION. Diagnostic and Statistical Manual of Mental Disorders, Fifth Edition (DSM-V). Arlington, VA: American Psychiatric Association, 2013. AMERICAN PSYCHIATRIC ASSOCIATION. Diagnostic and Statistical Manual of Mental Disorders, Third Edition (DSM-III). Arlington, VA: American Psychiatric Association, 1980.

BRAUNSTEIN, A. Classificar em Psiquiatria. México: Siglo XXI, 2013.

CALIMAN, L.V. A constituição sócio-médica do "fato TDAH”. Psicologia \& Sociedade, Belo Horizonte, v. 21, n. 1, p. 135-144, 2009.

CAMARGO Jr, K. et al. A subjetividade como anomalia: contribuições epistemológicas para a crítica do modelo biomédico. Ciência \& Saúde Coletiva. Rio de Janeiro, v. 16, n. 4, p. 1093-1103, 2006.

CASTIEL, L. A Saúde Persecutória e os limites da responsabilidade. Rio de Janeiro: Fiocruz, 2007. CAPONI, S. Loucos e degenerados: uma genealogia da psiquiatria ampliada. Rio de Janeiro: Fiocruz, Rio de Janeiro, 2012.

CONRAD, P. The Medicalization of Society. Baltimore: The Johns Hopkins University Press, 2007.

DESROSIÉRES, A. La politique des grands nombres: histoire de la raison statistique. Paris: La Découverte, 2010.

DUNKER, C.; NETO, F. A crítica psicanalítica do DSM-IV - breve história do casamento psicopatológico entre psicanálise e psiquiatria. Rev. Latinoam. Psicopat. Fund., São Paulo, v. 14, n. 4, p. 611-626, dez. 2011.

FRANCES, A. Opening Pandoras Box: The 19 Worst Suggestions For DSM5. Rev. Psychiatric Times, v. 1, n. 1, February 11, 2010.

Saving Normal: an insider's revolt against out-of-control psychiatric diagnosis, DSM-V, bg pharma, and the medicalization of ordinary life. New-York: Harper Collins Publisher, 2013a. 
DSM-5 continues to ignore criticism from petitioners. 2012. Disponível

em: <http://www.huffingtonpost.com/allen-frances/DSM-V-petition_b_1610569. html?view=print \&comm_ref=false>

. Psychosis risk syndrome is back to haunt us. Post Science. 2013b. Disponível em <http://www.huffingtonpost.com/allen-frances/psychosis-risk-syndrome-i_b_4343661.html>.

. DSM-V writing mistakes will cause great confusion. Post Science. 2013c. Disponível em: <http://www.huffingtonpost.com/allen-frances/dsm5-writing-mistakeswil_b_3419747.html>.

. DSM in philosophyland: curiouser and curiouser. In: PARIS, J.; PHILLIPS, J. (Eds.). Making the DSM-V concepts and controversies. New York: Springer, 2013d. p. 95-104. FOUCAULT, M. História de la Sexualidad I: la voluntad de saber. México: Siglo XXI, 1978. . El nacimiento de la clínica. México: Siglo XXI, 1987.

. Histoire de la folie à l'âge classique. Paris: Plon, 1961.

. Il faut defendre la societe. Paris: Gallimard, 1997.

. Las palabras y las cosas. México: Siglo XXI, 1983.

_. Le pouvoir psiquiatrique. Paris. Gallimard.2003.

. Les anormaux. Paris: Gallimard, 1999.

. Naissance de la biopolitique. Paris: Gallimard, 2005.

. Securité, territoire, population. Paris: Gallimard, 2004.

. Vigilar y castigar. México: Siglo XXI, 1979.

GARCIA MALDONADO, G. et al. El DSM-V. Luces y sombras de un manual no publicado. Retos y expectativas para el futuro. Revista Salud Mental. Madrid, n. 34. p. 367378, 2011.

HACKING, I. Making up people. London Review of Books. London, v. 28, n. 16, p. 2326, 2006.

. Lost in the forest. London Review of Books. London, v. 35, n. 15, p. 7-9, 2013.

HORWITZ, A. Creating mental illness. Chicago: The University of Chicago Press, 2002.

HORWITZ, A.; WAKEFIELD, J. The loss of sadness. Oxford: Oxford University Press, 2007.

HORWITZ, A.; WHOOLEY, O. The paradox of professional success: grand ambition, furious resistance, and the derailment of the DSM-V revision process. In PARIS, J.; PHILLIPS, J. (Eds.). Making the DSM-V concepts and controversies. New York: Springer, 2013. p. 75-94.

INSEL, T. Transforming diagnosis. 2013. Disponível em: <http://www.nimh.nih.gov// about/director/directors-biography.shtml>. 
KOTTOW, M. Hacking: lost in the forest. Revista Chilena de Salud Pública, Santiago de Chile, v. 17, n. 3, p. 307-315, 2013.

MOYNIHAN, R.; CASSELS, A. Medicamentos que nos enferman: la industria farmacéutica que nos convierte en pacientes. Barcelona: Contrapunto, 2006.

ORTEGA, F. Biopolíticas da saúde: reflexões a partir de Michel Foucault, Agnes Heller e Hannah Arendt. Interface, Comunicação, Saúde e Educação. Botucatu, v. 8, n. 14, p. 9-20, 2004. O sujeito cerebral e o movimento da neurodiversidade. $M A N A$, v. 14, n. 2, p. 477-509, 2008.

PARIS, J.; PHILLIPS, J. (Eds.). Making the DSM-V concepts and controversies. New York: Springer, 2013.

PAS ZERO DE CONDUIT. Disponível em: http://www.pasde0deconduite.org/. Acessado em: 12 dezs 2013.

PIGNARRE, P. Les malheurs des psys: psychotropes et médicalisation du social. Paris: La Découverte, 2006.

PHILLIPS, J. (Ed.). Bulletin of the Association for the Advancement of Philosophy and Psychiatry, v. 17, n. 1, 2010.

ROUDINESCO, E. Por qué el psicoanálisis? Buenos Aires: Paidós, 2013.

SADLER, J. Waiting for the miracle. In: PHILLIPS, J. (Ed.). Bulletin of the Association for the Advancement of Philosophy and Psychiatry, v. 17, n. 1, 2010.

SADLER, J. Considering the economy of DSM alternatives. In: PARIS, J.; PHILLIPS, J. (Eds.). Making the DSM-V concepts and controversies. New York: Springer, 2013. p. 21-38.

STOP DSM. To oppose the DSM-V is not to oppose psychiatry. Disponível em: <http://www. stop-dsm.org/index.php/en/>. Acesso em: $10 \mathrm{dez} 2013$. 


\section{$D S M-V$ as security device}

This paper aims to analyze two criticisms concerned with the publication of DSM-V that focused the attention of the international community: the criticism of Thomas Insel, Director of the National Institute of Mental Health (NIMH), and the criticism made by Allen Frances, who was the head of the task force that developed the DSM-IV. Both will be analyzed having as frame the courses given by Michel Foucault at the Collège de France, particularly The abnormals, Psychiatric power, and Security, territory and population. Besides these two criticisms, it will also analyze Ian Hacking's text Lost in the forest, published after the release of DSM-V. Hacking proposed in this paper that we must not pay attention to each new diagnostic category (the trees), but in the general diagnostic strategy presented in the manual, considered as a whole (the forest).

> Key words: DSM-5; Foucault; biopolitics; risk; psychiatry. 